\title{
Spatiotemporal analysis of precipitation trends under climate change in the upper reach of Mekong River basin
}

\author{
Feifei Wu ${ }^{1,2}$, Xuan Wang ${ }^{1,3 *}$, Yanpeng Cai ${ }^{3,4}$, Chunhui $\mathrm{Li}^{l}$ \\ ${ }^{1}$ Key Laboratory for Water and Sediment Sciences of Ministry of Education, School of \\ Environment, Beijing Normal University, Beijing 100875, China \\ ${ }^{2}$ Policy Research Center for Environment and Economy, Ministry of Environmental \\ Protection, Beijing 100029, China \\ ${ }^{3}$ State Key Laboratory of Water Environment Simulation, School of Environment, \\ Beijing Normal University, Beijing 100875, China \\ ${ }^{4}$ Institute for Energy, Environment and Sustainable Communities, University of Regina, \\ 120, 2 Research Drive, Regina, Saskatchewan S4S 7H9, Canada
}

\section{Abstract:}

Precipitation anomalies have greatly affected eco-hydrological processes in the upper reach of the Mekong River. In this research, an integrated spatiotemporal decomposition analysis method was proposed for the identification of precipitation trends under climate change at the basin scale. This method was a comprehensive use of multiple environmental statistical analysis approaches, including the S-mode empirical orthogonal function analysis, the inverse distance weighted interpolation, the Mann-Kendall trend test, the linear regression and the weighted moving average. Results indicated that precipitation trends were mainly obtained by two spatial-temporal variation patterns resulting from the decomposition of the original precipitation field. The primary spatial pattern (more than $40 \%$ variances) indicated that the annual and seasonal precipitation in the entire basin had a common variation trend. Moreover, variability of precipitation increased to the largest in the central basin and gradually decreased from north to south. Accordingly, precipitation-sensitive areas were mainly located in the east-central basin. The associated temporal trends showed that annual precipitation increased slightly over 1960 to 2009, and decreased significantly at the 5\% significance level since 2000. Spring precipitation increased significantly over the entire study period. The secondary spatial

*Corresponding author: Xuan Wang, School of Environment, Beijing Normal University, Beijing 100875, China.

E-mail address: wangx@bnu.edu.cn 
pattern extracted at least $15 \%$ of the variance and represented a north-south inverse-variation trend. The northern mountainous region was more sensitive to climate change. Temporal trend analysis showed that annual precipitation had an increasing trend in the northern region and a decreasing trend in the southern region. Precipitation in the northern region increased significantly at the $1 \%$ significance level in winter. The research results could form a basis for supporting basin-scale water resources management, especially in the mountainous basin.

Keywords: precipitation trends; integrated spatiotemporal decomposition and analysis; empirical orthogonal function analysis; Mann-Kendall trend test; Mekong River basin

\section{Introduction}

The well-evidenced climate warming has a cascade of impacts on many eco-hydrological processes (Cai et al., 2009; Johnson and Weaver, 2009; Dunn et al., 2012; Saurer, 2012; Wang et al., 2013). It is altering hydrological cycles and the associated precipitation patterns under multiple spatial and temporal scales, which in turn is affecting runoff formation and flow regimes (Beyene et al., 2010; Willems and Vrac, 2011; Nie et al., 2012). Among the factors that are influenced by climate change, the precipitation pattern is probably one of the most useful indicators to reflect and describe effects of changing climatic conditions. Even a minor perturbation in the precipitation pattern would result in a series of major impacts on the water system within a basin (Muzik, 2001; Minville et al., 2008; Ficklin et al., 2010). Owing to its sensitivity to climate change, any changes of the precipitation pattern have attracted much attention especially in river basins where water is mainly sustained by natural precipitation (Hayhoe et al., 2007; Bhutiyani et al., 2010; Seguí et al., 2010; Ward et al., 2011). This feature is particularly distinctive in most mountainous basins, where seasonal variations in precipitation are extremely sensitive to any changing climatic conditions (Sato, 2009; Frumau et al., 2011). Therefore, it is useful to investigate spatiotemporal variations of precipitation in a mountainous basin to help understand impacts of climate change on water systems at the river-basin scale.

Previously, many research efforts have been devoted to analyzing spatial and/or temporal variations of precipitation patterns in many watersheds across the world. Villar et al. (2009) examined precipitation variability over the period of 1964 to 2003 in the Amazon 
basin. Zhang et al. (2009) investigated the changing properties of precipitation concentration in the Pearl River basin, China. Blender (2011) evaluated long-term variability of runoff and precipitation patterns in the Yangtze River basin, and established statistical connections between such factors and East Asian monsoon. After a thorough investigation, Timbal and Hendon (2011) confirmed that Murray-Darling basin of Australia has been experiencing precipitation deficits. Most of these studies were based on various statistical analysis methods, which could facilitate understand spatiotemporal variations in precipitation patterns. Particularly, the method of empirical orthogonal function (EOF) analysis is considered as an effective way to decompose a complex spatiotemporal field into spatial and temporal dimensions. In recent decades, this method was widely adopted in atmospheric, hydrological, environmental, resources, and geographical studies (Jolliffe, 2002; Houser et al., 2008; Liu et al., 2009; Tan et al., 2010a,b,c; Xu et al., 2010).

Many parametric and non-parametric test methods were employed. For example, as a non-parametric method, the Mann-Kendall trend test is effective in dealing with long time-series hydrological and meteorological data that are not normal distributions. Comparatively, as one of the parametric test methods, the linear regression method is long on analyzing variation trends and precipitation intensities, especially when the sampling number of precipitation is small. Additionally, the moving average method was widely used in reflecting long-period features of many climatic factors. It has strength in acquiring potential long-term changes through smoothing short-term fluctuations of random climatic variables, and extracting periodic behaviors and changes of major climatic factors (William, 2007). Generally speaking, each method has both advantages and disadvantages. They can supplement each other for dealing with trend analysis and extracting impacts of climate change on water systems. Until now, few studies were conducted based on the integration of the three methods (i.e., EOF, Mann-Kendall trend test, and the moving average method). At the same time, most previous studies focused on major and/or inland basins. Few studies were conducted on mountainous regions at the basin scale. In such regions, effects of climate change may be amplified due to the discontinuance of air and vapor movement by mountains. This leads to a variety of complexities in analyzing spatiotemporal trends and distributions of precipitation, calling 
for an integration of the above-mentioned methods.

As one of the major international rivers in Asia, it is particularly necessary to analyze spatiotemporal variations of precipitation in the Mekong River basin, i.e., the Lancang River basin in China. This river is of great importance not only to southwestern China but also to Southeast Asia. It has diverse topographical conditions and a variety of climatic zones due to the existence of many high mountains and deep valleys in southwestern China. Moreover, precipitation anomalies have been frequently occurring in this region, posing a significant challenge to downstream water resources management (Eastham et al., 2008; Erwin, 2009). In order to further understand responses of this international river to climate change, a spatiotemporal analysis of precipitation trends in the Lancang River was conducted, which provided a basis for river basin management in southwestern China. For example, insignificant precipitation variations have been identified in the Lancang River basin and the Mekong River basin during the last 50 years (Li et al., 2011; Xue et al., 2011). Previous studies in this river basin mostly focused on annual variations in precipitation. The corresponding seasonal variations were scarcely reported, which could provide an in-depth and comprehensive view to identify precipitation anomalies (Cheng and Xie, 2008; He and Zhang, 2009; Zhai et al., 2010; Li et al., 2011). Thus, a complete evaluation of precipitation variations is desired in the basin under multiple temporal and spatial scales, which could help formulate comprehensive basin management plans in southwestern China and Southwestern Asia.

The objective of this research is to propose an integrated spatiotemporal decomposition analysis method (ISTDAM) to help investigate long-term spatiotemporal precipitation trends in the upper reach of Mekong River basin (Lanchang River). Relationships between such trends and the changing climate conditions will be established and analyzed. Spatiotemporal variations in annual and seasonal precipitation from 1960 to 2009 will be analyzed through the adoption of ISTDAM. This method is based on an integration of multiple statistical analysis methods, including approaches of spatial-mode empirical orthogonal function (i.e., S-mode EOF) analysis, inverse distance weighted (IDW) interpolation, Mann-Kendall trend test, linear regression, and weighted moving average. Such an objective entails: (a) examination of spatial variations in precipitation at annual and seasonal scales from 1960 to 2009, and (b) investigation of temporal trends of 
precipitation associated with spatial variations. Results of this study will provide useful guidance for facilitating formulation of strategic decision alternatives regarding international river affairs and basin-scale water resources management.

\section{Material and method}

\subsection{Overview of the Lancang River basin}

The Lancang River basin in China is the upper reach of the Mekong River basin. It approximately lies between 21 to $29^{\circ} \mathrm{N}$ and 98 to $102^{\circ} \mathrm{E}$ in Yunnan province (Fig. 1). The basin is situated at the southeastern margin of the Tibetan Plateau within the Hengduan Mountains. It is affected by complex seasonal monsoons such as the southwest monsoon from the Indian Ocean and Bay of Bengal, the south-branch of the westerlies, and the local climate of the Tibetan Plateau (Xiao et al., 2010). With a coarse-bed mountain stream, the Lancang River basin includes mountain-valley regions with elevations ranging from less than $500 \mathrm{~m}$ a.s.l to greater than 4,000 $\mathrm{m}$ a.s.l. The northern region of the basin is typically a range-gorge landscape characterized by north-south mountains and valleys aligned from west to east whose elevation is above $3,000 \mathrm{~m}$ ( $\mathrm{Li}$ et al., 2011). Due to the complex topographical conditions, seasonal monsoons and climatic zones, precipitation is sensitive to climate change. Spatiotemporal variations of precipitation trends have distinctly local features.

The monthly precipitation data from 11 meteorological stations (Deqin, Weixi, Dali, Baoshan, Jingdong, Lincang, Simao, Lancang, Jinghong, Jiangcheng, and Mengla) of the National Climate Center, China Meteorological Administration were selected (Fig. 1). Geographic characteristics of the stations are summarized and presented in Table 1. According to the method developed by Jones et al. (1986), the missing data from Deqin station from Jun to Oct in 1968 were interpolated as the mean values of actual monthly precipitation in 1966, 1967, 1969 and 1970. Differing from most plain and inland basins, the existence of both rainy and dry seasons is the main feature in this mountainous basin. The dry season refers to the period from November to April. Comparatively, the rainy season lasts from May to October. To analyze intra and inter-annual precipitation trends, annual and seasonal mean values of precipitation data were calculated. 


\subsection{Development of an integrated spatiotemporal decomposition analysis method}

In this research, an integrated spatiotemporal decomposition analysis method (ISTDAM) was proposed to identify spatiotemporal variations in precipitation under climate change at multiple time scales in the upper reach of the Mekong River basin. This method contains procedures of spatiotemporal decomposition (STD) and spatiotemporal analysis (STA), with an integration of multiple statistical analysis methods, including methods of S-mode EOF analysis, IDW interpolation, Mann-Kendall trend test, linear regression and weighted moving average.

Normally, the EOF analysis method can be divided into spatial and temporal modes (i.e., $\mathrm{S}$ - and T-modes). The main differences between these two modes are the purposes and processing methods of the time series data. In the S-mode EOF, each column represents one set of observations, with each element holding the data from the $r$ different locations. The matrix with original data can be defined as $L(r \times t)$.Comparatively, in the T-mode, the matrix with original data can be defined as $L(t \times r)$. In this research, the number of stations (i.e. 11 stations) is less than that of observations (i.e. 50 years). Therefore, the

S-mode EOF needs to be adopted for the analysis of spatial variations of precipitation and the associated temporal trends. The time series data should be presented in rows and normalized in rows. A schematic diagram of the proposed ISTDAM is presented in Fig. 2. The detailed procedure can be described as follows:

Step 1. Establish the spatiotemporal matrix $L(r \times t)$ based on annual or seasonal precipitation (P), which contains $t$ observations from $r$ stations and can be presented as follows;

$L(r \times t)=\left[\begin{array}{ccc}\ldots & \rightarrow & L_{1 t} \\ \downarrow & \ldots & \ldots \\ L_{r 1} & \ldots & \ldots\end{array}\right]$

Step 2. Normalize each row of matrix $L$ to generate matrix $X(r \times t)$; 
Step 3. Determine the spatial covariance matrix $C(r \times r)$ :

$C(r \times r)=\left(X \bullet X^{T}\right) / t=\left[\begin{array}{ccc}\ldots & \rightarrow & C_{1 r} \\ \downarrow & \ldots & \ldots \\ C_{r 1} & \cdots & \ldots\end{array}\right]$

where $X^{T}$ is the transpose of $X$;

Step 4. Obtain eigenvalue matrix $\Lambda(r \times r)$ and eigenvector matrix $V(r \times r)$ through S-mode Eigen-analysis:

$C \bullet V=\Lambda \bullet V$

where each column of matrix $V=\left[V_{E O F 1}, V_{E O F 2}, \ldots, V_{E O F r}\right]$ represents a spatial pattern, which can be referred to $V_{E O F}$. The matrix $\Lambda$ is a diagonal matrix containing the corresponding eigenvalues as $\left(\lambda_{1}, \lambda_{2}, \ldots, \lambda_{r}\right)$, and $\lambda_{1}>\lambda_{2}>\ldots>\lambda_{r}$;

Step 5. Generate time series matrix $T$ that are associated with spatial matrix $V$. It can be obtained by the projection of $V$ onto the matrix $X$ :

$T=\left(V^{T} \bullet X\right)$

where each row of matrix $T=\left[\begin{array}{c}T_{P C 1} \\ T_{P C 2} \\ \ldots \\ T_{P C r}\end{array}\right]$ represents temporal trend associated with spatial pattern, which can be referred to $T_{P C}$.

Step 6. Retain the leading $V_{E O F} / T_{P C}$ pairs. The variance of the $V_{E O F i} / T_{P C i}$ pair can be expressed by the associated eigenvalue $\lambda_{i}$, with the first pair being the most important followed by the second, and so on (Yu and Chu, 2010). North et al (1982) suggested a 
significance test for each $V_{E O F} / T_{P C}$ pair based on the number of independent sampling locations and eigenvalues. The confidence interval is defined as $\lambda \pm \Delta \lambda$. If the confidence interval is smaller than the spacing between this eigenvalue and the next one, then this pair is statistically significant;

Step 7. Analyze spatial patterns that are indicated by $V_{E O F s}$. The major leading $V_{E O F S}$ can be further analyzed through IDW interpolation, which can successfully identify leading spatial-variation patterns of precipitation;

Step 8. Analyze the associated temporal variations that are reflected by $T_{P C s}$. This can be achieved through combining methods of Mann-Kendall trend test, weighted moving average method, and linear regression. The Mann-Kendall trend test is a non-parametric method for detecting trends in data series over a certain period. It was widely used in hydrological and meteorological studies (Chen et al., 2011; Monk et al., 2011). Under a significance level (i.e., $\alpha$ ), a statistical value can be assigned according to Hamed and Rao (1998). A positive value of $Z$ indicates an upward trend, while a negative value indicates a downward trend. In this research, $\alpha=0.01$ and 0.05 are to be applied, respectively.

Through the above procedure, ISTDAM can effectively integrate STD and STA into a general modeling framework, enhancing the existing methods in dealing with small samples of data in the basin. The major leading $V_{E O F} / T_{P C}$ pairs gleaned from STD were analyzed through the procedure of STA to reveal spatial patterns and associated temporal trends in-depth and accurately. Therefore, ISTDAM can facilitate successful reflection of precipitation variations under climate change, particularly in basins with diverse climatic zones and poor data.

\section{Results and discussion}

\subsection{Spatial analysis of precipitation}

3.1.1. Annual and seasonal precipitation

Annual and seasonal distribution of precipitation is illustrated in Fig. 3. Results indicated 
that annual average precipitation generally increased from north to south within the basin. Large variability was present, with precipitation ranging from $<650$ to $>2,000 \mathrm{~mm}$. The lowest precipitation was observed at Deqin station in the southeast margin of the Tibetan Plateau, which was greatly affected by cold air of the plateau. In contrast, the highest precipitation was observed at Jiangcheng station, which was affected by hot air of the tropical region.

Generally speaking, the Lancang River basin has complex precipitation patterns, which are influenced by topographical conditions, monsoon and latitude. Annual precipitation decreases from west to east in the north part of the basin. Annually, two centers with high precipitation amounts form in the south. In the north region (i.e., areas to the north of $27^{\circ} \mathrm{N}$ ), most mountains are aligned north-to-south. Comparatively, most rivers are aligned west-to-east ( $\mathrm{Li}$ et al., 2011). The mountains are obstructions to the East Asian monsoon in the west-east direction and a thoroughfare in the south-north direction. The mountains pose an obstacle to the movement of the East Asian monsoon. Therefore, average precipitation amount in the west part (i.e., the upwind slope of the mountains) is much larger than that of the east in the leeward slope. In the south region, valleys are relatively wide with gradual slopes. The elevation is less than $1,000 \mathrm{~m}$, forming a corridor for the transport of water vapor in the rainy Asian monsoon. Affected by water vapor originating from the Bay of Bengal and the South China Sea, high precipitation centers form at Lancang and Jiangcheng stations. The existence of a clear dry-wet season is an important climatic characteristic in the basin. The complexity of the atmospheric circulation is higher in the wet season than in the dry season (Fig. 3). Moreover, affected by the south-branch of the westerlies and the Tibetan Plateau, precipitation was abundant in the northern mountainous region and relatively scarce in most of the basin in spring and winter (Xiao et al., 2010; Zhu et al., 2011). If drought occurred, it would seriously affect the basin.

\subsubsection{Spatial patterns of precipitation variations}

Annual and seasonal precipitation from 1960 to 2009 was analyzed through the S-mode EOF. Sets of $V_{E O F i} / T_{P C i}$ pairs $(i=1,2, . ., r)$ were generated based on equations (3) and (4), respectively. Normally, whether precipitation is high or low cannot be determined 
through the analysis of eigenvector values. However, such values can definitely reflect the distribution of the precipitation variation field in the basin. According to the results of statistically significance test conducted by North et al. (1982), the first two pairs of $V_{E O F i} / T_{P C i}(i=1,2)$ were found to be significant (see Table 2).

\subsubsection{Primary spatial pattern of precipitation variations}

The $V_{E O F 1}$ of annual and seasonal precipitation variations could represent most features of spatial variations in precipitation (Fig. 4). Values of eigenvectors in $V_{E O F 1}$ were all positive. Precipitation in the entire basin had a common variation trend, accounting for over $40 \%$ of the total variance contributions. This indicated that the phase consistency was a leading feature in spatial variations of annual and seasonal precipitation within the basin. Thus, precipitation variations were affected by the large-scale atmospheric circulation to a large degree (Tan et al., 2009). The result was in accordance with the reported precipitation variation trend in Hengduan Mountains (Li et al., 2011).

The spatial distribution of $V_{E O F 1}$ for annual precipitation variation is shown in Fig. 4(a). Although the entire basin shared a similar precipitation variations trend, variability of precipitation increased to maximum in the central basin and gradually decreased from north to south. Regions with high values were mostly located in the east part of the basin, centered on Jingdong, Lincang and Simao stations. This was attributed to the terrain and monsoon (Xiao et al., 2010). With fragmented terrain featured by mid-mountain and wide-valley, the middle basin was subject to monsoon transitions. The cold air transport from the monsoon weakened from east to west. Therefore, the sensitive region was located in the east-central basin.

Seasonal precipitation variations are presented in Fig. 4 (b)-(e), based on the results of $V_{E O F 1}$. Similar to annual variation patterns, sensitive regions with high $V_{E O F 1}$ values were mostly located in the central part of basin. The area of the sensitive region in the dry season was larger than that in the wet season. This suggests that the extremes occurring in the dry season affect a larger area than those in the wet season. In summer, the high-value regions were centered on Lincang station. This pattern was changed with a northward movement in autumn. The northward movement of the sensitive region in the wet season 
could be associated with the tropical oceanic air mass transported by the southwest monsoon moving north (Thomas, 1993).

\subsubsection{Secondary spatial pattern of precipitation variations}

The $V_{E O F 2}$ of annual and seasonal precipitation variations extracted at least $15 \%$ of the variance of spatial variations in precipitation (Fig. 5). Elements of eigenvectors in $V_{E O F 2}$ included both positive and negative values. The zero isolines, oriented southwest-northeast through the basin, divided the basin into two sub-regions. Regions with positive and negative values showed an inverse phase in response to precipitation changes. A north-south inverse-variation pattern was identified and represented a distinct feature of precipitation through $V_{E O F 2}$ analysis. Also, it showed a zonal pattern of precipitation variations from north to south in the basin.

Comparatively, based on $V_{E O F 2}$, the spatial pattern of annual precipitation variations is shown in Fig. 5(a). The zero isoline was aligned with Lincang and Jingdong stations in the southwest-northeast direction. For the region with positive values, precipitation in the northern end centered on Deqin and Weixi stations was considered sensitive to climate change. For the region with negative values, high value areas were distributed in the southern region, centered on Lincang and Simao stations. Within the basin, the northern region was the most sensitive area to precipitation change (the value is greater than 0.60 ). Two reasons can explain this issue. Firstly, high-elevation regions may probably experience changing climatic conditions at a faster rate than low-elevation regions (Beniston, 2003; Liu et al., 2009). Within the basin, elevation decreases from the northernmost with the highest point of 3,319 $\mathrm{m}$ a.s.l at Deqin station to the south and the lowest point at Jinghong station, $582 \mathrm{~m}$ a.s.1. Therefore the northern region, with high mountains and valleys, was the most sensitive to any changing climatic conditions in the basin. Secondly, the Lancang River basin lies in the eastern Asian monsoon region. The weakening eastern Asian monsoon and the complex topographic conditions in the northern region may have an increased sensitivity of precipitation under any changing climatic conditions (Ding et al., 2010).

Similar to patterns of annual precipitation variations, results of $V_{E O F 2}$ for seasonal precipitation showed a consistent north-south inverse-variation pattern divided by the 
zero isoline. Main differences were the distributions of high-value areas in the south region. The climate of the Lancang River basin is mainly affected by the Indian monsoon in summer and the southern stream of the westerly winds in winter (Li, 1993; Tan et al., 2009). In summer, the most intense water vapor convergence regions were located in the Bay of Bengal and the South China Sea in East Asia (Ding et al., 2010). Water vapor transport from the southwest monsoon was stronger than that from the southeast monsoon. Hence, the west-southwest region was more sensitive to climatic factors than the east in the south region in summer. However, in winter the atmospheric circulation was relatively slow, and the high $V_{E O F 2}$ value areas werer mainly concentrated in the southern end of the basin.

\subsection{Temporal analysis of precipitation}

According to equation (4), sets of $V_{E O F} / T_{P C}$ can be used for help reveal temporal trends in precipitation. In order to detect temporal trends and magnitudes of precipitation, the Mann-Kendall trend test, the 3-year moving average method with binomial coefficient weights and the linear regression method were used in this research.

\subsubsection{Temporal trends associated with the primary spatial pattern}

According to the results of $T_{P C l}$, a higher value of $T_{P C l}$ represented a higher level of precipitation. Fig. 6 shows the values of $T_{P C l}$ that are associated with $V_{E O F l}$ of annual and seasonal precipitation. Results indicated that the Lancang River basin was becoming warmer and wetter over the period of 1960 to 2002 under global warming, similar to the situations in the Tibetan Plateau and the Yunnan-Guizhou Plateau (Ma et al., 2006; Xu et al., 2008). However, there was no significant change in precipitation over the past 50 years in the entire Mekong basin (Xue et al., 2011). A lower annual precipitation during the middle period of 1970s was observed compared with that in the early period of 1980s. As its upper reach, the Lancang River basin exhibited a slight and insignificant increasing precipitation, in accordance with the precipitation trend in southwestern China (Wang and Zhou, 2005; Qin et al., 2010). However, annual precipitation showed a significant downward trend at the $5 \%$ level of significance since 2002. It suggested that the basin is prone to droughts in recent years. This was particularly true in 2009, in which the largest 
negative value of $T_{P C l}$ was obtained. Also, many devastating climatic extremes have occurred in the last decades in China, such as the severe drought in southwest China from autumn 2009 to spring 2010 (Lu et al., 2011).

The Mann-Kendall trend test results for seasonal $T_{P C l}$ are summarized in Table 3. The 3-year weighted moving average method and the linear regression method are used for analyzing the trend variations of the precipitation synchronously (see Fig. 6). Seasonally, precipitation increased significantly in spring over the period from 1960 to 2009. That was consistent with the increasing spring precipitation in Tibet Plateau and different from the decreasing trend in most parts of the Yangtze River basin and the Yellow River basin (Zhang et al., 2012). In winter, a slightly decreasing trend was identified, while an increasing trend was identified in summer. The tendency of dry winter and wet summer was a distinct shift in the basin. This was different from the case of southwestern China, where precipitation increased significantly in winter and decreased significantly in summer (Qin et al., 2010), prone to trigger a higher probability of droughts in the dry season and floods in the wet season.

Over the period of 2000 to 2009, different from the insignificantly increasing precipitation in spring and summer, precipitation in autumn and winter decreased slightly in the basin. Low precipitation featured by negative values of $T_{P C l}$ was dominant in winter after 2000. Seasonal and annual precipitation was consistently low in 2009. Moreover, the obtained negative values in autumn and winter were relatively large over the period of 1960 to 2009. These results suggested that although the basin had a downtrend in precipitation since 2000, the severe drought event actually emerged as early as autumn and was maintained in winter in 2009. The less-than-normal water vapor and warmer-than-normal air temperature both contributed to the maintenance of this drought (Lu et al., 2011).

\subsubsection{Temporal trends associated with the secondary spatial pattern}

Fig. 7 shows the values of $T_{P C 2}$ associated with the $V_{E O F 2}$ of annual and seasonal precipitation variations. In the $V_{E O F 2}$, an inverse variation trend was detected between the northern and southern region within the basin. $T_{P C 2}$ represented the temporal trend in regions with positive values. The Mann-Kendall trend test results for annual and seasonal 
$T_{P C 2}$ are summarized in Table 4.

The 3-year weighted moving average method and the linear regression method were used for analyzing the trend variations of the precipitation synchronously (Fig. 7). As shown in Fig. 7(a), an increasing trend was identified for annual precipitation in the north of the basin while a decreasing trend in the south. This was consistent with the precipitation variation trend in Yunnan province found by Ma et al. (2006). It confirmed the result that the south region was more vulnerable to droughts than the north region. It was evident that the northern region has exhibited a decreasing precipitation at the 5\% level of significance since 2000. This suggested that though a wet tendency was detected during the last 50 years, severe droughts had been frequently observed in recent years.

Seasonally, precipitation in the northern region decreased insignificantly in spring and summer. Comparatively, precipitation in the region increased slightly in autumn and significantly in winter. Precipitation change in the Hengduan Mountains significantly increased from north to south during winter monsoon period (Li et al., 2011). Wetter winters occurred in the period of 1960 to 2009 in the north region of the basin. Differing from the variation trend over the entire study period, precipitation decreased in almost all of the seasons except the winter since 2000. Precipitation in spring and summer declined more rapidly compared with that in autumn. Based on the calculation results, negative

values of $T_{P C 2}$ were dominant in spring. The frequency of spring drought increased, and could have severe impacts on agricultural production in the basin.

\section{Conclusions}

In this research, an integrated spatiotemporal decomposition analysis method (ISTDAM) was proposed for supporting the identification of precipitation variations under climate change in the upper reach of Mekong River (i.e., the Lancang river basin in China). It was based on the integration of multiple statistical analysis methods, including methods of the S-mode empirical orthogonal function (EOF) analysis, the inverse distance weighted (IDW) interpolation, the Mann-Kendall trend test, the linear regression, and the weighted moving average, which could facilitate analysis of complex variations of precipitation. At the same time, it could reflect precipitation variations over multiple spatial and temporal scales, and help formulate water resources management strategies at 
this international river basin. The main conclusions related to the basin are as follows:

(a) The primary spatial pattern which extracted at least $40 \%$ of the variance indicated that the annual and seasonal precipitation in the entire basin had a common variation trend. Moreover, variability of precipitation increased to the largest in the central basin and gradually decreased from north to south. Accordingly, sensitive areas were mainly located in the east-central basin. Annual precipitation increased slightly over 1960 to 2009 . A significant downward trend was identified at the 5\% level of significance since 2000. Seasonally, precipitation in spring significantly increased over the entire study period. At the same time, tendencies of dry winter and wet summer were observed, respectively.

(b) The secondary spatial pattern extracted at least $15 \%$ of the variance and represented a north-south inverse-variation trend. The northern mountainous region was more sensitive to climate change. An increasing trend was identified for the annual precipitation over the entire study period. This has decreased in the northern region since 2000. Seasonally, precipitation decreased insignificantly in spring and summer, increased slightly in autumn, and significantly in winter over the period of 1960 to 2009.

Overall, these results revealed long-term spatiotemporal precipitation trends, which can provide a scientific basis for helping generate basin-scale water resources management plans. In order to fully understand responses of water systems under climate change, further studies need to be conducted to help detect the relationship between precipitation anomaly and precipitation variations in the basin.

\section{Acknowledgements}

This research was supported by the State Key Program of National Natural Science of China (No.50939001) and the National Science Foundation for Innovative Research Group (No. 51121003). We greatly appreciate Prof. Bin Chen and Qiang Liu for their valuable advice on improving the manuscript. Also, we would like to extend special thanks to the editor and the anonymous reviewers for all their detailed comments and valuable suggestions in greatly improving the quality of this paper. 


\section{References}

Beniston, M., 2003. Climatic change in mountain regions: a review of possible impacts. Climatic Change 59, 5-31.

Beyene, T., Lettenmaier, D.P., Kabat, P., 2010. Hydrologic impacts of climate change on the Nile River Basin: implications of the 2007 IPCC scenarios. Climatic Change 100, $433-461$.

Bhutiyani, M.R., Kale, V.S., Pawar, N.J., 2010. Climate change and the precipitation variations in the northwestern Himalaya: 1866-2006. International Journal of Climatology 30(4), 535-548.

Blender, R., Zhu, X.H., Zhang, D., Fraedrich, K., 2011. Yangtze runoff, precipitation, and the East Asian monsoon in a 2800 years climate control simulation. Quaternary International 244, 194-201.

Chen, Y.Q., Zhang, Q., Lu, X.X., Zhang, S.R., Zhang, Z.X., 2011. Precipitation variability (1956-2002) in the Dongjiang River (Zhujiang River basin, China) and associated large-scale circulation. Quaternary International 244, 130-137.

Cheng, J., Xie, M., 2008. The analysis of regional climate change features over Yunnan in recent 50 years. Progress in Geography 27, 19-26.

Cai, Y.P., Huang, G.H., Tan, Q., Chen, B. 2009. Identification of optimal strategies for improving eco-resilience to floods in ecologically vulnerable regions of a wetland. Ecological Modelling 222(2), 360-369.

Ding, Y.H., Liu, Y.J., Sun, Y., Song, Y.F., 2010. Weakening of the Asian Summer Monsoon and Its Impact on the Precipitation Pattern in China. International Journal of Water Resources Development 26(3), 423-439.

Dunn, S.M., Brown, I., Sample, J., Post, H., 2012. Relationships between climate, water resources, land use and diffuse pollution and the significance of uncertainty in climate change. Journal of Hydrology 434-435, 19-35.

Eastham, J., Mpelasoka, F., Mainuddin, M., Ticehurst, C., Dyce, P., Hodgson, G., 2008. Mekong River Basin Water Resources Assessment: Impacts of Climate Change. Canberra, Australia: CSIRO: Water for a Healthy Country National Research Flagship.

Erwin, K.L., 2009. Wetlands and global climate change: the role of wetland restoration in 
a changing world. Wetlands Ecology and Management 17, 71-84.

Ficklin, D.L., Luo, Y.Z., Luedeling, E., Gatzke, S.E., Zhang, M.H., 2010. Sensitivity of agricultural runoff loads to rising levels of $\mathrm{CO} 2$ and climate change in the San Joaquin Valley watershed of California. Environmental Pollution 158(1), 223-234.

Frumau, K.F.A., Bruijnzeel, L.A., Tobón, C., 2011. Scientific Briefing: Precipitation measurement and derivation of precipitation inclination in a windy mountainous area in northern Costa Rica. Hydrological Processes 25, 499-509.

Hamed, K.H., Rao, A.R., 1998. A modified Mann-Kendall trend test for autocorrelated data. Journal of Hydrology 204, 180-196.

Hayhoe, K., Wake, C.P., Huntington, T.G., Luo, L.F., Schwartz, M.D., Sheffield, J., et al. 2007. Past and future changes in climate and hydrological indicators in the US Northeast. Climate Dynamics 28(4), 381-407.

He, Y.L., Zhang, Y.P., 2009. Adaptation Assessment of Eco-environment in the Longitudinal Range-Gorge Region under the Changing Climate. Journal of Mountain Science 27, 300-305.

Houser, C., Hapke, C., Hamilton, S., 2008. Controls on coastal dune morphology, shoreline erosion and barrier island response to extreme storms. Geomorphology 100, 223-240.

Johnson, T., Weaver, C., 2009. A framework for assessing climate change impacts on water and watershed systems. Environmental Management 43, 118-134.

Jolliffe, I.T., 2002. Principal Component Analysis, Second Edition.

Jones, P.D., Raper, S.C.B., Bradley, R.S., 1986. Northern Hemisphere Surface Air Temperature Variations: 1851-1987. Journal of Climate and Applied Meteorology 25, 161-179.

Li, K., 1993. Annals of Yuanmou County. Yunnan People's Press. pp. 30-51.

Li, Z., He, Y., Wang, C., Wang, X., Xin, H., Zhang, W., et al., 2011. Spatial and temporal trends of temperature and precipitation during 1960-2008 at the Hengduan Mountains, China. Quaternary International 236, 127-142.

Liu, Y., Huang, G.H., Cai, Y.P., Cheng, G.H., Niu, Y.T., An, K. 2009. Development of an inexact optimization model for coupled coal and power management in North China. Energy Policy 37(11), 4345-4363. 
Liu, X.D., Cheng, Z.G., Yan, L.B., Yin, Z.Y., 2009. Elevation dependency of recent and future minimum surface air temperature trends in the Tibetan Plateau and its surroundings. Global and Planetary Change 68, 164-174.

Lu, E., Luo, Y.L., Zhang, R.H., Wu, Q.H., Liu, L.P., 2011. Regional atmospheric anomalies responsible for the 2009-2010 severe drought in China. Journal of Geophysical Research 116, D21114, doi:10.1029/2011JD015706.

Ma, Z.F., Peng, J., Gao, W.L., Tian, H., 2006. Climate variation of Southwest China in recent 40 years. Plateau Meteorology 25(4), 633-642 (in Chinese).

Minville, M., Brissette, F., Leconte, R., 2008. Uncertainty of the impact of climate change on the hydrology of anordic watershed. Journal of Hydrology 358(1-2), $70-83$.

Monk, W.A., Peters, D.L., Curry, R.A., Baird, D.J., 2011. Quantifying trends in indicator hydroecological variables for regime-based groups of Canadian rivers. Hydrological Processes 25, 3086-3100.

Muzik, I., 2001. Sensitivity of hydrologic systems to climate change. Canadian Water Resources Journal 26(2), 233-253.

Nie, C.J., Lia, H.R., Yang, L.S., Ye, B.X., Dai, E.F., Wu, S.H., et al, 2012. Spatial and temporal changes in extreme temperature and extreme precipitation in Guangxi. Quaternary International 263, 162-171.

North, G.R., Bell, T.L., Cahalan, R.F., Moeng, F.J., 1982. Sampling errors in the estimation of empirical orthogonal functions. Monthly Weather Review 110, 699706.

Qin, N.X., Chen, X., Fu, G.B., Zhai, J.Q., Xue, X.W., 2010. Precipitation and temperature trends for the Southwest China: 1960-2007. Hydrological Processes 24, 3733-3744.

Sato, T., 2009. Influences of subtropical jet and Tibetan Plateau on precipitation pattern in Asia: Insights from regional climate modeling. Quaternary International 194, 148-158.

Saurer, M., 2012. On the reconstruction of precipitation in temperature-limited environments by the use of stable isotopes in tree-rings. Quaternary International 279-280, 430.

Seguí, P.Q., Ribesb, A., Martinb, E., Habetsc, F., Boéd, J., 2010. Comparison of three 
downscaling methods in simulating the impact of climate change on the hydrology of Mediterranean basins. Journal of Hydrology 383(1-2), 111-124.

Tan, L.C., Cai, Y.J., Cheng, H., An, Z.S., Edwards, R.L., 2009. Summer monsoon precipitation variations in central China over the past 750 years derived from a high-resolution absolute-dated stalagmite. Palaeogeography, Palaeoclimatology, Palaeoecology 280, 432-439.

Tan, Q., Huang, G.H., Cai, Y.P. 2010a. A superiority-inferiority-based inexact fuzzy stochastic programming approach for solid waste management under uncertainty. Environmental Modeling \& Assessment 15(5), 381-396.

Tan, Q., Huang, G.H., Cai, Y.P. 2010b. Waste management with recourse: An inexact dynamic programming model containing fuzzy boundary intervals in objectives and constraints. Journal Of Environmental Management 91(9), 1898-1913.

Tan, Q., Huang, G.H., Cai, Y.P. 2010c. Radial-interval linear programming for environmental management under varied protection levels. Journal of the Air \& Waste Management Association 60(9),1078-1093.

Thomas, A., 1993. The onset of the rainy season in Yunnan province, PR China and its significance for agricultural operations. International Journal of Biometeorology 37, 170-176.

Timbal, B., Hendon, H., 2011. The role of tropical modes of variability in recent rainfall deficits across the Murray-Darling Basin. Water Resources Research 47(1), W00G09.

Villar, J.C.E., Ronchail, J., Guyot, J.L., Cochonneau, G., Naziano, F., Lavado, W., et al. 2009. Spatio-temporal rainfall variability in the Amazon basin countries (Brazil, Peru, Bolivia, Colombia, and Ecuador). International Journal of Climatology 29, 1574-1594.

Wang, Y.Q., Zhou, L., 2005. Observed trends in extreme precipitation events in China during 1961-2001 and the associated changes in large-scale circulation. Geophysical Research Letters 32, L09707.

Wang, S.J., Jiao, S.T., Xin, H.J., 2013. Spatio-temporal characteristics of temperature and precipitation in Sichuan Province, Southwestern China, 1960-2009. Quaternary International 286, 103-115.

Ward, E., Buyaert, W., Peaver, L.,Wheater, H., 2011. Evaluation of precipitation products 
over complex mountainous terrain: A water resources perspective. Advances in water resources 34(10), 1222-1231.

William J.B., 2007. A multidisciplinary approach (second edition). Cambridge University Press, Cambridge, United Kingdom.

Willems, P., Vrac, M., 2011. Statistical precipitation downscaling for small-scale hydrological impact investigations of climate change Original Research Article. Journal of Hydrology 402(3-4), 193-205.

Xiao, X.Y., Shen, J., Wang, S.M., Xiao, H.F., Tong, G.B., 2010. The variation of the southwest monsoon from the high resolution pollen record in Heqing Basin, Yunnan Province, China for the last 2.78 Ma. Palaeogeography, Palaeoclimatology, Palaeoecology 287(1), 45-57.

Xu, Z.X., Zhang N., 2006. Long-term trend of precipitation in the Yellow River basin during the past 50 years. Geographical Research 25(1), 27-34 (in Chinese).

Xu, Z.X., Gong, T.L., Li, J.Y., 2008. Decadal trend of climate in the Tibetan Plateau-regional temperature and precipitation. Hydrological Processes 22(16), 3056-3065.

Xu, L.G., Zhou, H.F., Liang, C., Du, L., Li, H., 2010. Spatial and temporal variability of annual and seasonal precipitation over the desert region of China during 1951-2005. Hydrological Processes 24, 2947-2959.

Xue, Z., Liu, J.P., Ge, Q., 2011. Changes in hydrology and sediment delivery of the Mekong River in the last 50 years: connection to damming, monsoon, and ENSO. Earth Surface Processes and Landforms 36, 296-308.

Yu, H.L., Chu, H.J., 2010. Understanding space-time patterns of groundwater system by empirical orthogonal functions: A case study in the Choshui River alluvial fan, Taiwan. Journal of Hydrology 381, 239-247

Yue, S., Pilon, P., Phinney B. et al., 2002. Power of the Mann-Kendall and Spearman's rho tests for detecting monotonic trends in hydrological series. Journal of Hydrology $259,254-271$

Zhai, H.J., Cui, B.S., Hu, B., Zhang, K.J., 2010. Prediction of river ecological integrity after cascade hydropower dam construction on the mainstream of rivers in Longitudinal Range-Gorge Region (LRGR), China. Ecological Engineering 36, 
361-372.

Zhang, Q., Xu, C.Y., Gemmer, M., Chen, Y.Q., Liu, C.L., 2009. Changing properties of precipitation concentration in the Pearl River basin, China. Stochastic Environmental Research and Risk Assessment 23, 377-385.

Zhu, X.H., Bothe, O., Fraedrich, K., 2011. Summer atmospheric bridging between Europe and East Asia: Influences on drought and wetness on the Tibetan Plateau. Quaternary International 236, 151-157.

Zhang, Q., Sun, P., Vijay, P.S., Chen, X.H., 2012. Spatial-temporal precipitation changes (1956-2000) and their implications for agriculture in China. Global and Planetary Change 82-83, 86-95.

\section{List of Figure and Table Captions}

Fig. 1. Map of the study area with the location of the stations.

Fig. 2. Integrated spatiotemporal decomposition analysis method.

Fig. 3. Spatial distribution of annual and seasonal precipitation in the Lancang River basin (a: annual; b: spring; c: summer; d: autumn; e: winter).

Fig. 4. $V_{E O F 1}$ of annual and seasonal precipitation variations (a: annual; b: spring; c: summer; d: autumn; e: winter).

Fig. 5. $V_{E O F 2}$ of annual and seasonal precipitation variations (a: annual; b: spring; c: summer; d: autumn; e: winter).

Fig. 6. $T_{P C l}$ associated with $V_{E O F 1}$ of annual and seasonal precipitation variations (a: annual; b: spring; c: summer; d: autumn; e: winter).

Fig. 7. $T_{P C 2}$ associated with $V_{E O F 2}$ of annual and seasonal precipitation variations (a: annual; b: spring; c: summer; d: autumn; e: winter).

Table 1. Geographic characteristics of stations.

Table 2. Variance contributions (\%) of the first two $V_{E O F s}$.

Table 3. Trend statistics $\mathrm{Z}$ for $T_{P C l}$ of precipitation variations by Mann-Kendall trend test.

Table 4. Trend statistics $\mathrm{Z}$ for $T_{P C 2}$ of precipitation variations by Mann-Kendall trend test. 


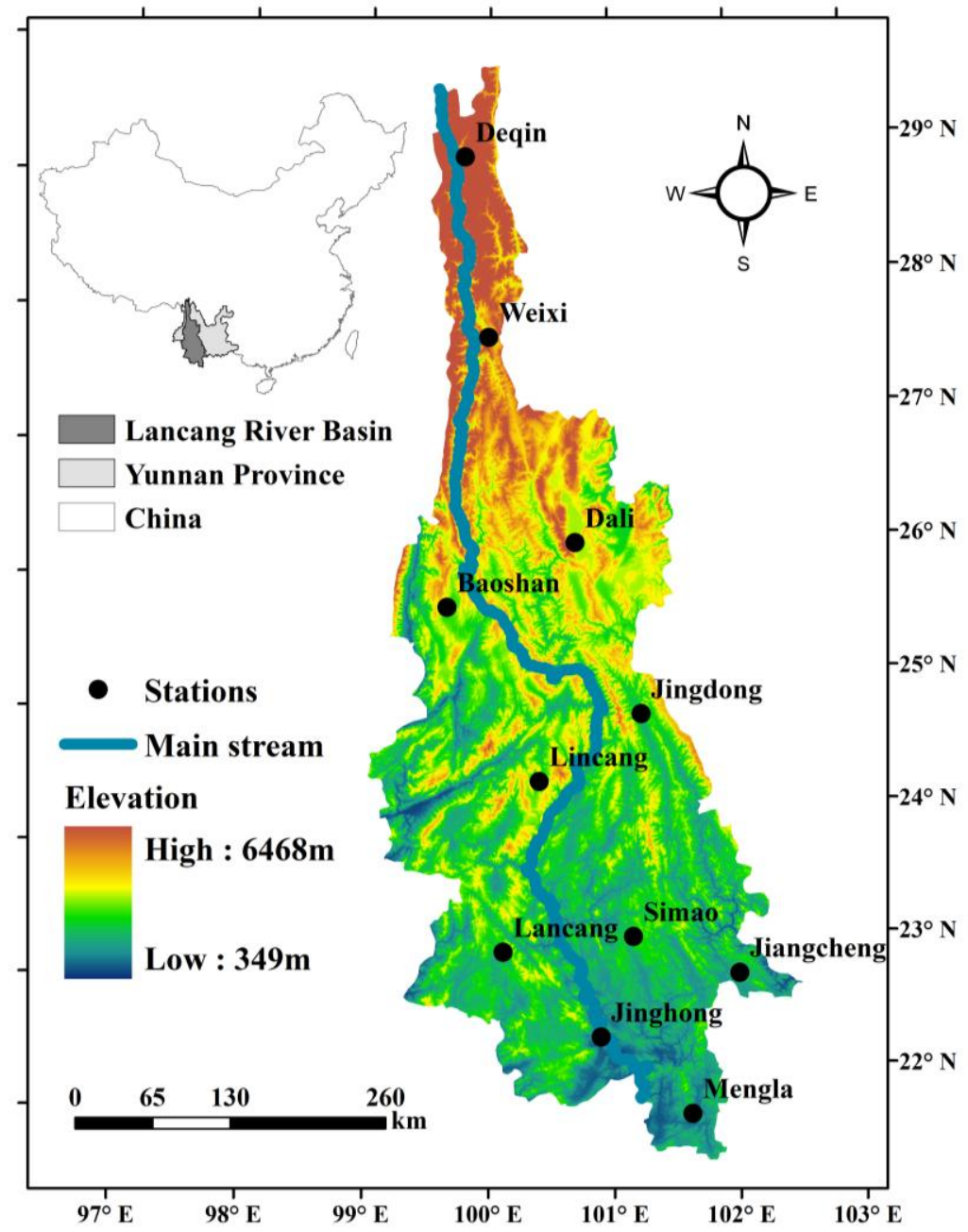

Fig. 1. Geographical map of the study area with the location of stations. 


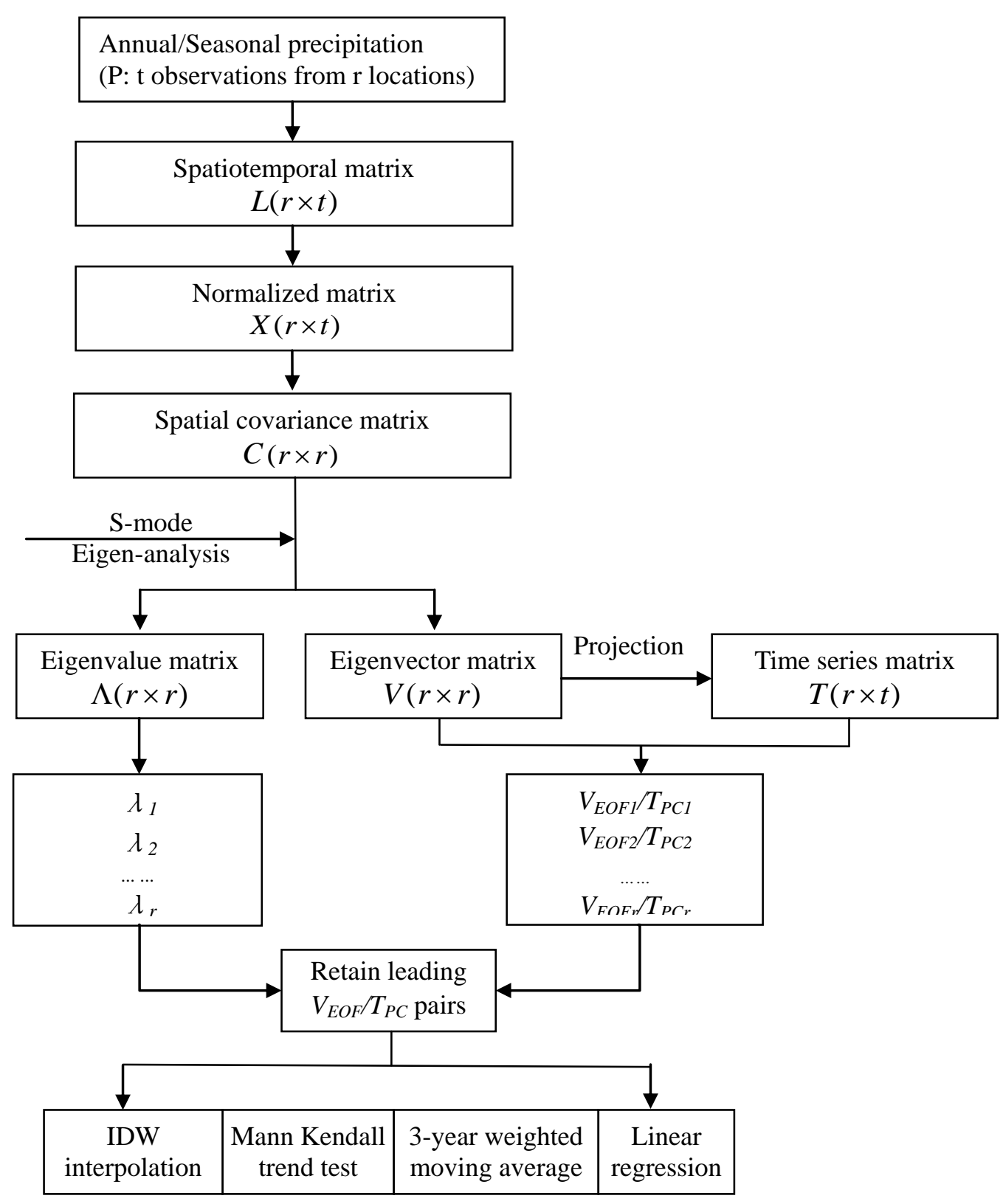

Spatiotemporal Decomposition

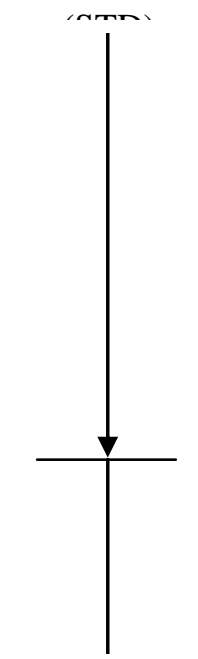

Spatiotemporal Analysis

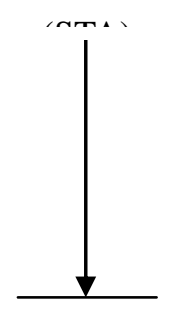

Fig. 2. Integrated spatiotemporal decomposition analysis method. 


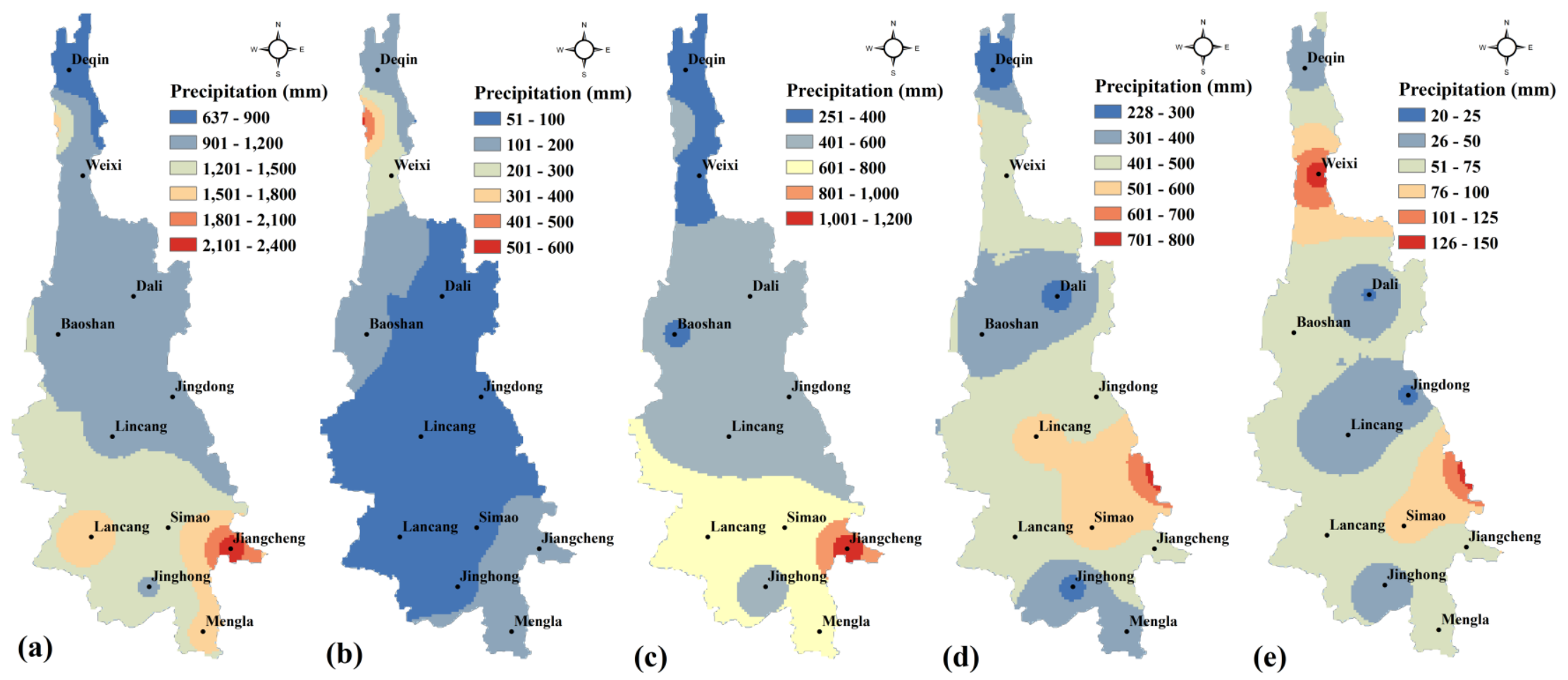

Fig.3. Spatial distribution of annual and seasonal precipitation in the Lancang River basin (a: annual; b: spring; c: summer; d: autumn; e: winter). 

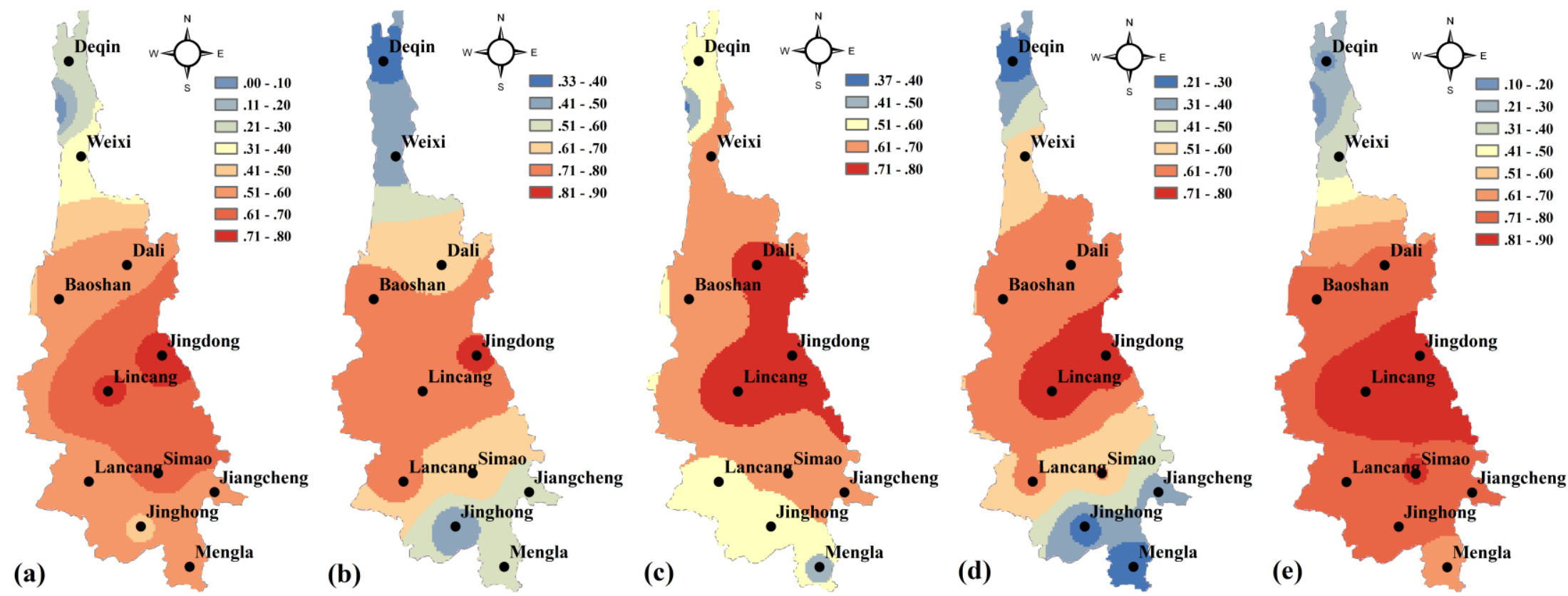

Fig.4. $V_{E O F 1}$ of annual and seasonal precipitation variations (a: annual; b: spring; c: summer; d: autumn; e: winter). 

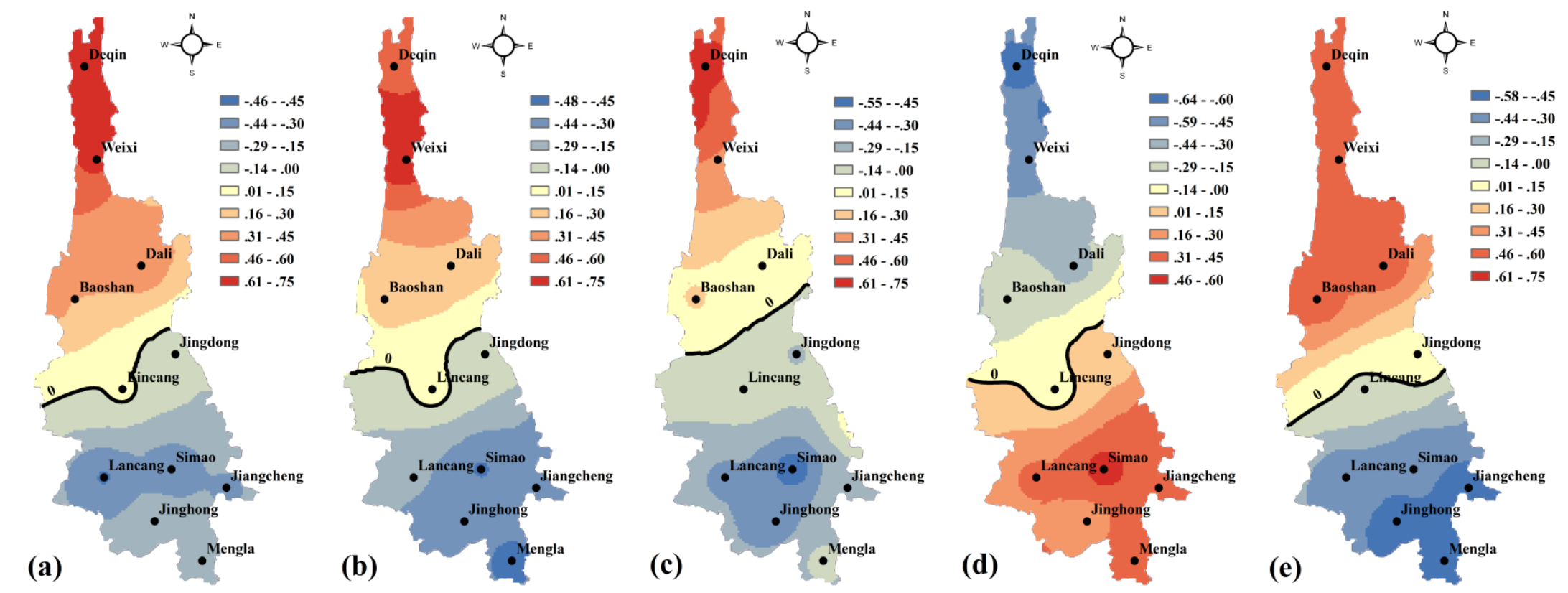

Fig.5. $V_{E O F 2}$ of annual and seasonal precipitation variations (a: annual; b: spring; c: summer; d: autumn; e: winter). 

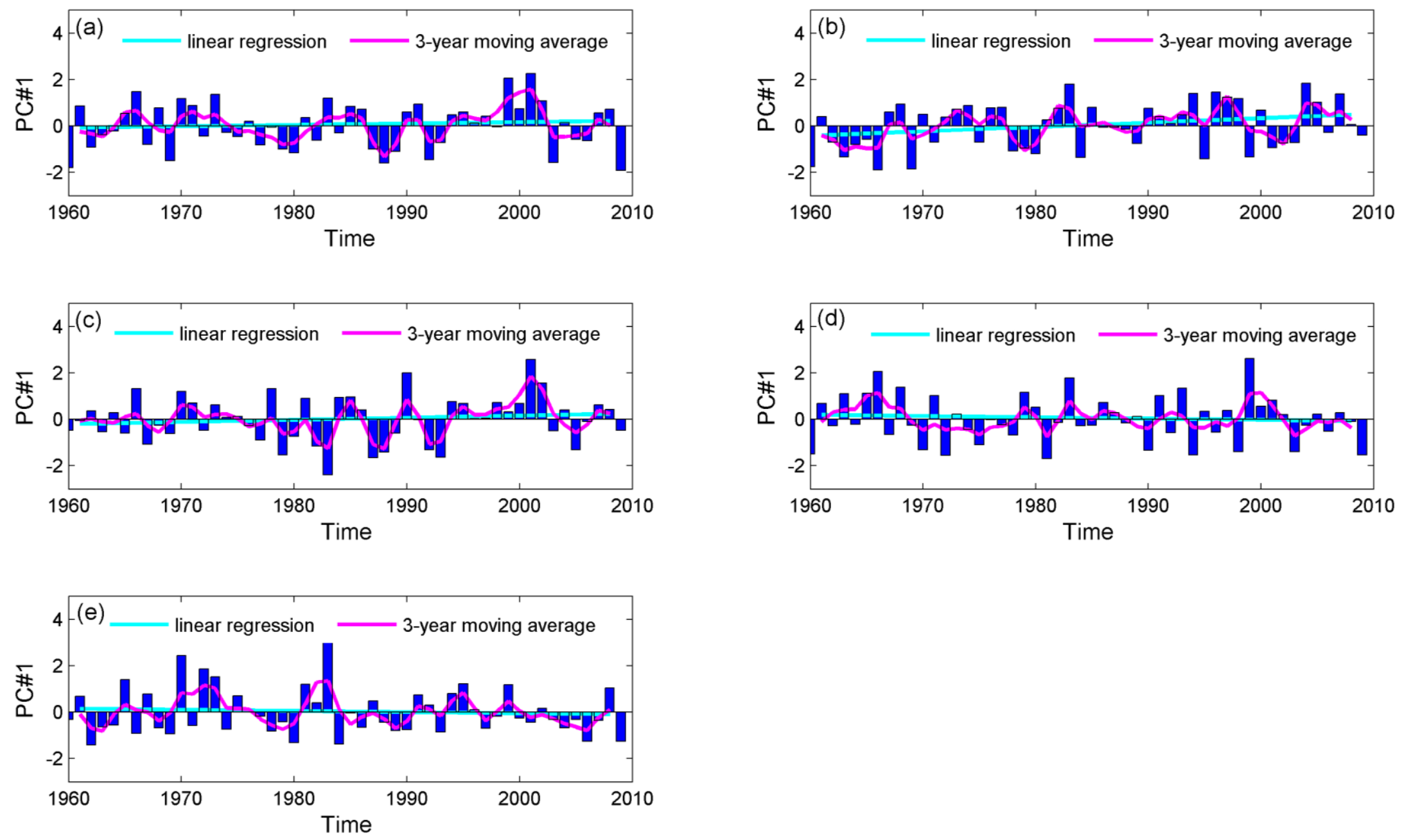

Fig.6. $T_{P C l}$ associated with $V_{E O F l}$ of annual and seasonal precipitation variations (a: annual; b: spring; c: summer; d: autumn; e: winter). 

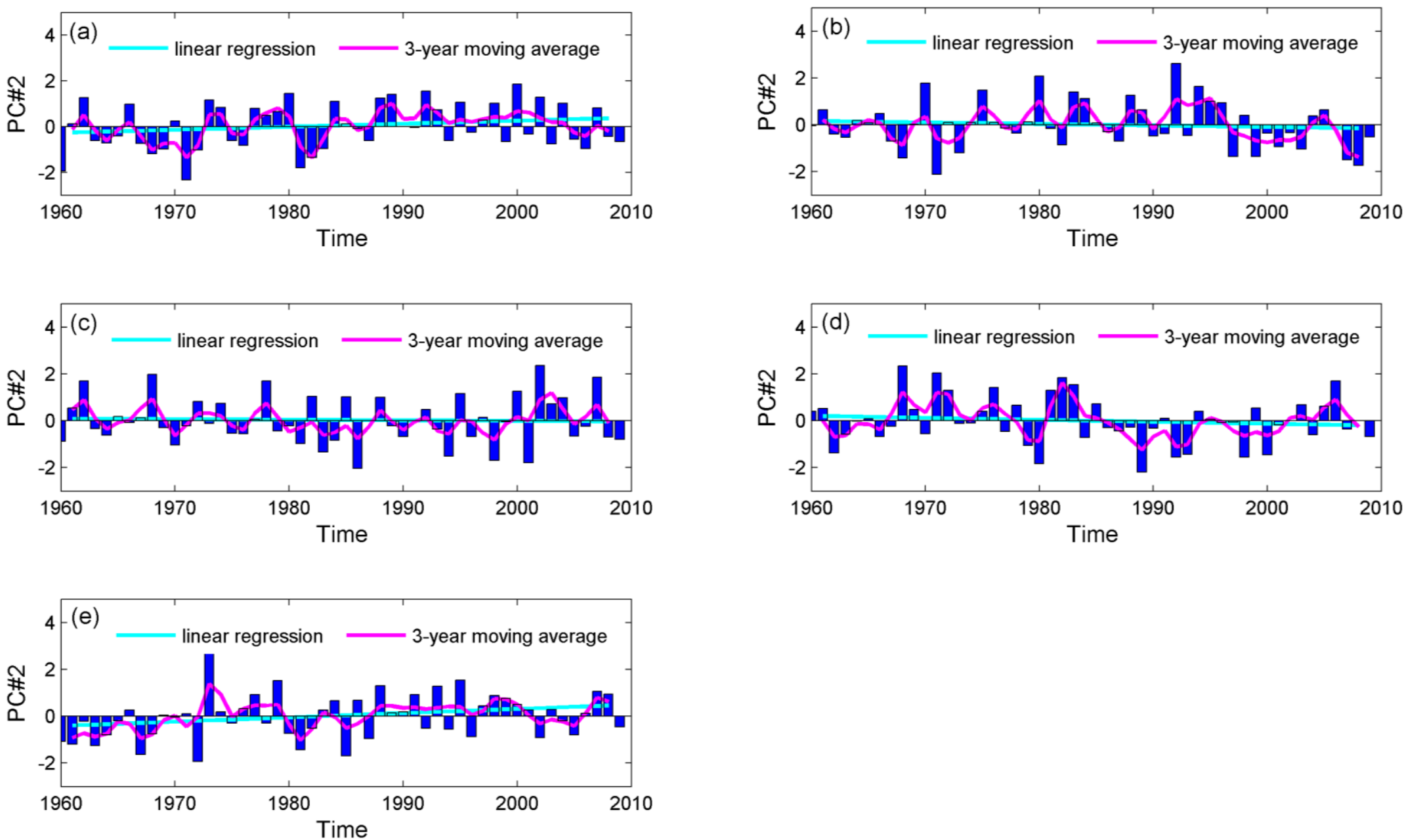

Fig.7. $T_{P C 2}$ associated with $V_{E O F 2}$ of annual and seasonal precipitation variations (a: annual; b: spring; c: summer; d: autumn; e: winter). 
Table 1. Geographic characteristics of stations.

\begin{tabular}{lrrc}
\hline Station & Latitude(N) & Longitude(E) & Elevation(m a.s.l) \\
\hline Deqin & $28^{\circ} 29^{\prime} \mathrm{N}$ & $98^{\circ} 55^{\prime} \mathrm{E}$ & 3319 \\
Weixi & $27^{\circ} 10^{\prime} \mathrm{N}$ & $99^{\circ} 17^{\prime} \mathrm{E}$ & 2326 \\
Dali & $25^{\circ} 42^{\prime} \mathrm{N}$ & $100^{\circ} 11^{\prime} \mathrm{E}$ & 1990 \\
Baoshan & $25^{\circ} 07^{\prime} \mathrm{N}$ & $99^{\circ} 11^{\prime} \mathrm{E}$ & 1652 \\
Jingdong & $24^{\circ} 28^{\prime} \mathrm{N}$ & $100^{\circ} 52^{\prime} \mathrm{E}$ & 1162 \\
Lincang & $23^{\circ} 53^{\prime} \mathrm{N}$ & $100^{\circ} 05^{\prime} \mathrm{E}$ & 1502 \\
Simao & $22^{\circ} 47^{\prime} \mathrm{N}$ & $100^{\circ} 58^{\prime} \mathrm{E}$ & 1302 \\
Lancang & $22^{\circ} 34^{\prime} \mathrm{N}$ & $99^{\circ} 56^{\prime} \mathrm{E}$ & 1054 \\
Jinghong & $22^{\circ} 00^{\prime} \mathrm{N}$ & $100^{\circ} 47^{\prime} \mathrm{E}$ & 582 \\
Jiangcheng & $22^{\circ} 35^{\prime} \mathrm{N}$ & $101^{\circ} 51^{\prime} \mathrm{E}$ & 1120 \\
Mengla & $21^{\circ} 29^{\prime} \mathrm{N}$ & $101^{\circ} 34^{\prime} \mathrm{E}$ & 631 \\
\hline
\end{tabular}


Table 2. Variance contributions (\%) of the first two $V_{E O F s}$.

\begin{tabular}{llll}
\hline Precipitation & $\begin{array}{l}\text { Explained variance } \\
\text { of } \boldsymbol{V}_{\text {EOF1 }}\end{array}$ & $\begin{array}{l}\text { Explained variance } \\
\text { of } \boldsymbol{V}_{\text {EOF2 } 2}\end{array}$ & $\begin{array}{l}\text { Cumulated } \\
\text { explained } \\
\text { variance }\end{array}$ \\
\hline Year & 42 & 15 & 57 \\
Spring & 46 & 15 & 61 \\
Summer & 41 & 17 & 58 \\
Autumn & 40 & 16 & 56 \\
Winter & 50 & 19 & 69 \\
\hline
\end{tabular}


Table 3. Trend statistics $\mathrm{Z}$ for $T_{P C l}$ of precipitation variations by Mann Kendall trend test.

\begin{tabular}{lcccccc}
\hline Season & $\mathbf{1 9 6 0 - 2 0 0 9}$ & $\mathbf{1 9 6 0 - 1 9 6 9}$ & $\mathbf{1 9 7 0 - 1 9 7 9}$ & $\mathbf{1 9 8 0}-\mathbf{1 9 8 9}$ & $\mathbf{1 9 9 0}-\mathbf{1 9 9 9}$ & $\mathbf{2 0 0 0 - 2 0 0 9}$ \\
\hline Year & 0.27 & 0.72 & -2.15 & -0.89 & 0.18 & $-1.61^{*}$ \\
Spring & $1.87^{*}$ & 0.54 & -0.36 & -0.72 & 0.18 & 0.89 \\
Summer & 0.6 & -1.07 & -1.79 & -0.36 & 0.36 & -1.43 \\
Autumn & -0.38 & 1.25 & 0.89 & 0.36 & 0.72 & $-1.67^{*}$ \\
Winter & -0.37 & -0.72 & -2.15 & -0.72 & 0.72 & -1.25 \\
\hline
\end{tabular}

*Trend statistically significant at the 5\% confidence level. 
Table 4. Trend statistics $\mathrm{Z}$ for $T_{P C 2}$ of precipitation variations by Mann Kendall trend test.

\begin{tabular}{lrrrrrr}
\hline Season & $\mathbf{1 9 6 0 - 2 0 0 9}$ & $\mathbf{1 9 6 0}-\mathbf{1 9 6 9}$ & $\mathbf{1 9 7 0}-\mathbf{1 9 7 9}$ & $\mathbf{1 9 8 0}-\mathbf{1 9 8 9}$ & $\mathbf{1 9 9 0}-\mathbf{1 9 9 9}$ & $\mathbf{2 0 0 0 - 2 0 0 9}$ \\
\hline Year & 1.19 & -1.07 & 0.89 & 1.43 & -0.72 & $-1.79^{*}$ \\
Spring & -1.09 & -1.07 & -0.18 & -0.72 & -1.07 & -0.72 \\
Summer & -0.42 & 0.72 & 0.72 & 0.36 & -0.54 & -1.25 \\
Autumn & -0.7 & 0.72 & -0.72 & -1.25 & 0.72 & 0.36 \\
Winter & $2.29^{* *}$ & 1.25 & 1.16 & 1.43 & 0.18 & 0.18 \\
\hline
\end{tabular}

*Trend statistically significant at the 5\% confidence level.

$* *$ Trend statistically significant at the $1 \%$ confidence level. 